\title{
THE APPLICATION OF SURFACE MOUNT PROCESSES FOR THE ECONOMICAL PRODUCTION OF HIGH-ASPECT-RATIO MICROCHANNEL ARRAYS
}

\author{
B.K. Paul, N. Sharma and T. Doolen \\ Department of Industrial and Manufacturing Engineering, Oregon State University, 118 Covell Hall, \\ Corvallis, OR 97330, e-mail: brian.paul@orst.edu
}

\begin{abstract}
This paper reports on the feasibility of using surface mount technology (SMT) assembly processes and materials to produce highly parallel, high-aspect ratio microchannel arrays. Experimental results show that the fabrication of high-aspect-ratio ( $>40: 1)$ microchannel arrays is possible using solder paste, screen printing, and reflow bonding. A simple model and empirical examination verifies that very little solder is wicked into the channel during reflow. The use of low bonding temperatures (under $300^{\circ} \mathrm{C}$ ) and pressures results in well aligned, parallel channels with low levels of warpage. Channel height variation within these microchannel arrays was measured to be less than $\pm 1.2 \%$ of the overall mean channel height of $270.9 \mu \mathrm{m}$. Gravity effects on three channel devices were found to be insignificant. The microlaminated devices were found to tolerate an air pressure of 1.72 bar (25 psi) without leakage though it is expected that higher air pressures are possible as the devices were not tested to failure.
\end{abstract}

Keywords: surface mount technology (SMT), microlamination, microchannel arrays, precision bonding, micro energy and chemical systems (MECS). 


\section{Introduction}

Micro Energy and Chemical Systems (MECS) are a family of microfluidic devices that rely on arrays of embedded microchannels for the bulk processing of mass and energy. A MECS device will typically have overall system dimensions on the order of 1 to $100 \mathrm{~cm}$, but will include embedded arrays of microchannels where channel heights are on the order of 25 to 250 micrometers $(\mu \mathrm{m})$. Sizes of other features within microchannels may extend well below $10 \mu \mathrm{m}$ including, for example, contactor pores below $5 \mu \mathrm{m}$, or catalyst features and immobilized nanoparticles below $1 \mu \mathrm{m}$. Because of the broad range of dimensions, MECS devices are considered multi-scale systems. Applications of MECS devices include heat exchange (Drost, 1999), advanced climate control (Drost, 1999; Martin, Bennett, \& Johnston, 1995), solvent separation (Martin, Matson, \& Bennett, 1999; TeGrotenhuis, Cameron, Butcher, Martin, \& Wegeng, 1999), fuel processing (Tonkovich, Zilka, LaMont, Wang, \& Wegeng, 1999; Holladay, Jones, Phelps, \& Hu, 2002), microdialysis (Martin, Matson, Bennett, \& Hammerstrom, 1998), bioreactors and micromixers (Palmer, Zeng, \& Penny, 2001) among others.

One class of MECS devices with current appeal are distributed thermal management systems including compact, heat-actuated heat pumps. It is estimated that these systems can be used to reduce the heating and cooling costs of an office building by over $25 \%$ by eliminating energy losses due to ducts and heat pump cycling (Drost et al., 2000). A key impediment to the proliferation of this type of MECS technology is economical production. Generally speaking, MECS devices are fabricated using a process architecture known as microlamination. Figure 1 shows a schematic of a microlamination architecture involving the patterning and bonding of thin layers of 
material called laminae (Paul \& Peterson, 1999). Materials are typically chosen based on mechanical, thermal and/or chemical properties though optical, physical and electrical properties can also be important. Raw material can be metal foils, thin film polymers or green ceramics. Lamina patterning typically includes either surface machining, through cutting, molding or forming processes. Once patterned, the laminae are registered relative to each other and bonded together in a stack to make a monolithic device.

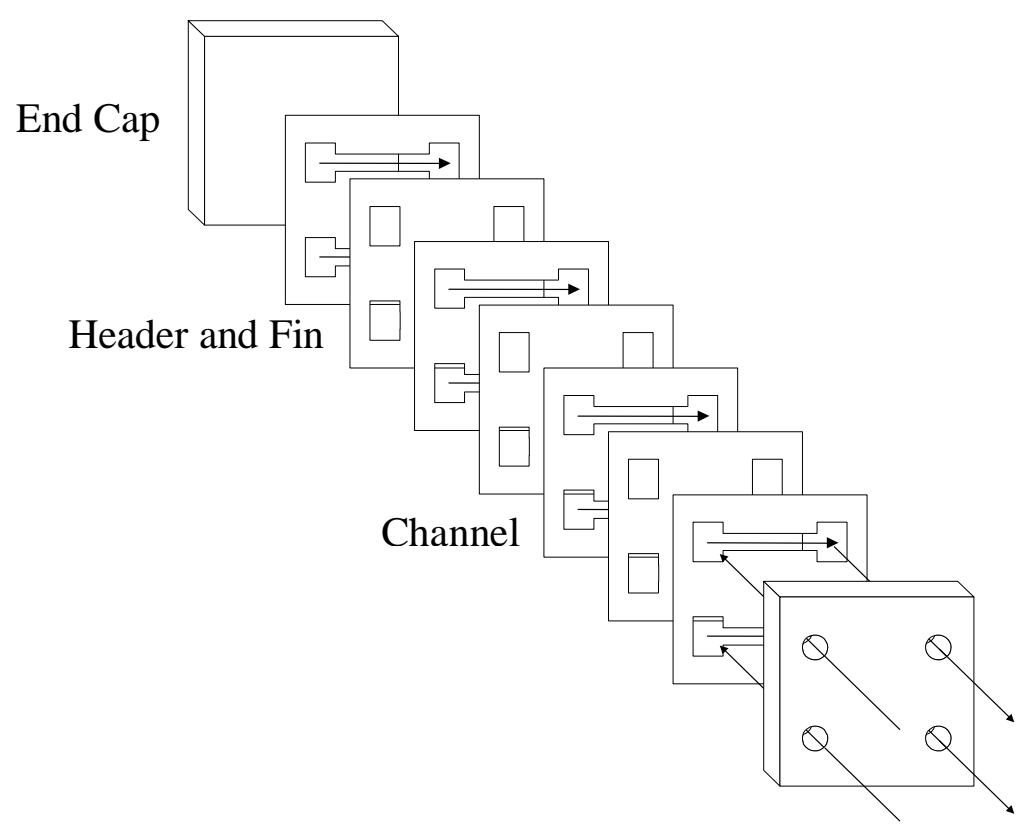

Figure 1. Microlamination scheme used to fabricate a dual micro-channel array. Arrows show direction of fluid flow.

Initial investigations into the economics of microlamination have shown that in certain architectures, bonding dominates the costs of microlamination (Porter, Paul, \& Ryuh, 2002) though more recently it has been shown that costs are driven by the number of laminae and the size of the substrate to be bonded (Sharma, Porter, \& Paul, 2003). A variety of bonding techniques have been used to fabricate MECS devices including diffusion bonding (Kanlayasiri \& Paul, 2004; Wegeng, Drost, \& McDonald, 1997; Paul, 
\& Peterson, 1999), micro-projection welding (Paul \& Terhaar, 2000; Paul, \& Peterson, 1999), adhesive bonding (Martin, et. al., 1998, Paul, \& Peterson, 1999), diffusion soldering and brazing (Gabriel, Paul, Wilson, \&. Alman, 2001; Anderson, 1989; Paul, \& Peterson, 1999), and ultrasonic welding (Paul, \& Peterson, 1999; Anderson, 1989; Wegeng et al., 1997). For certain microchannel geometries, it has been shown that selection of the bonding technique can be critical to the development of hermetic bonds (Gabriel et al., 2001). While bonding methods seem to impact both the economics and technical feasibility of MECS devices, much more process research has been conducted investigating micromachining processes than precision bonding technologies.

One promising avenue for addressing some of the economical and technological issues associated with the production of MECS devices involves the application of surface mount technology (SMT) assembly processes and materials. SMT assembly is the method of attaching leaded and non-leaded electrical components (transistors, resistors, capacitors, etc.) to the surface of printed circuit boards. SMT includes three process steps: (1) solder printing; (2) component mounting; and (3) reflow bonding. These process steps mirror the fabrication steps in a microlamination process. SMT solder paste bonding contrasts with other solid state bonding processes such as diffusion bonding, diffusion brazing and diffusion soldering, which have much longer cycle times and much tighter "fit up" requirements.

It has been shown that the unit cost of MECS devices which have been diffusion bonded (DB) could go down by more than 50\% if these SMT solder printing and reflow bonding processes were used instead (Sharma, Porter, \& Paul ,2003; Sharma \& Paul, 2003). This is due to both the reduction in the number of laminae as well as a reduction 
in cycle time (from hours to minutes). Further, by using these particular SMT processes, very little, if any, bonding pressure is necessary. This has an advantage for bonding complex microchannel systems where transmission of bonding pressure is difficult (Paul et al., 2001).

The SMT platform has several advantages over existing methods for fabricating MECS devices. In addition to better economics and ease of automation, the SMT process requires lower bonding temperatures and pressures. Lower bonding temperatures enable the integration of functionalized surfaces inside of microchannels albeit reducing the operating temperature of the device. Lower bonding pressures reduce the likelihood of unwanted microchannel warpage (in addition to providing a route to more complex geometries). Microchannel height deviations caused by the high bonding pressures within the diffusion bonding process have been found to be significant (Kanlayasiri et al., 2004; Wattanutchariya, 2002; Wattanutchariya \& Paul, 2004). In addition, the precision of SMT processes has advanced to allow for solder dimensions well below $25 \mu \mathrm{m}$ with the placement and soldering of packages on the order of $25 \times 50 \mu \mathrm{m}$. These dimensions are sufficient for MECS applications that normally require lateral dimensions on the $\mathrm{mm}$ scale. Finally, the use of SMT processes may provide a platform for integrating electronics within non-silicon MECS devices. It is possible, for example, to use the solder printing process not only for shaping microchannels, but also for preparing solder pads for SMT component placement. Should the laminae be made out of an insulator, it is possible to have embedded printed circuits with solder pads. This would be followed by component mounting through the use of standard pick and place equipment. The reflow bonding process would then be used to not only create the final microchannels, 
but also to solder paste reflow bond the components to the substrate. As the need for integrating sensors within MECS devices grows, having a technology platform in which electronics could be added to the substrate simultaneous to the building of the microchannel array could provide a significant integration and economic advantage.

Challenges associated with the application of SMT to the production of microchannel arrays mainly revolve around the capillary action of liquid solder adjacent to microchannels. In addition, it is unclear what effects gravity will have on microchannel arrays while the solder is molten. Lower channels would be expected to have more weight on them and may result in a reduction in the channel height from top to bottom. The following sections describe a protocol for overcoming these challenges and present results suggesting the technical feasibility of using SMT processes to produce a microlamination architecture.

\section{Process Validation}

Copper shim stock, which was $203 \mu \mathrm{m}$ (0.008 inches) thick, was used to produce the test articles for process validation. The shim stock used was alloy 110 copper $(99.9 \%$ copper). Kester-256 no-clean tin-lead eutectic solder alloy (Sn63-Pb37) was used for the bonding of laminae. Low-residue, no-clean flux was used for localized wetting of the copper where solder paste was not applied but was required to wet the surface. The test article design involved a stack of seven copper laminae. The three different lamina geometries used in the test device (interface plate, spacer/channel, and bottom end cap) are illustrated in Figure 2. The overall device dimensions were $4.4 \mathrm{~cm}$ x $1.9 \mathrm{~cm}$. The interface plate allows interconnection with the test loop for leakage tests. The spacer acts 


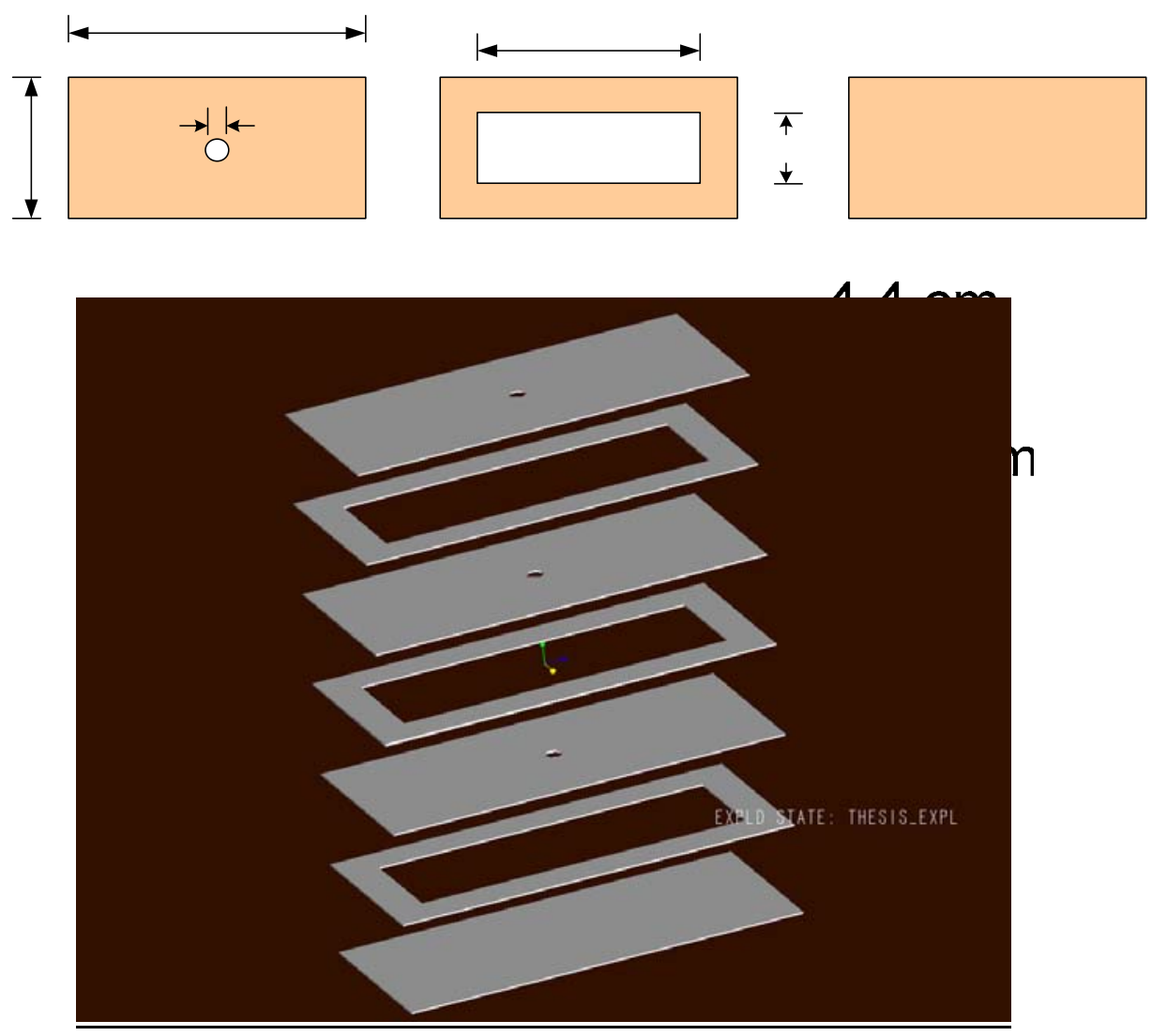

(d)

Figure 2. Geometry (a) Interface plate for the single-pass fluid flow. (b) Spacer which acts as the channel for the fluid flow. (c) End cap. (d) Exploded view of the device.

as a microchamber for testing leakage. The spacer is also critical for controlling the wetting behavior of the solder during reflow. Channel height is defined by the thickness of the spacer and the volume of solder paste after reflow.

Process validation involved fabrication of six, 3-channel devices. Half of the devices were checked for uniformity in channel height and half were checked for leakage. Channel height uniformity was determined by metallographic analysis of cross sections of the microchannels. All of the measurements were taken using a video micrometer at 50X magnification on an optical microscope. The resolution of the microscope used for these measurements was $2 \mu \mathrm{m}$ at a magnification of 50X. A gauge repeatability and 
reproducibility (R\&R) study was performed on the microscope with three different operators. The computations were performed using an ANOVA. It was concluded that the effect of operators and the effect of part-operator interaction were not significant (pvalues $=0.137$ and 0.837 , respectively).

Since the sample size was small, a Kruskal-Wallis nonparametric analysis was performed to compare the average channel heights of the three samples. The analysis was performed to test the null hypothesis that the three sample means were equal. The test statistic was compared with the Chi-square distribution to verify the null hypothesis. Similarly, the top, middle and bottom channel heights of each device were compared using the Kruskal-Wallis nonparametric approach. This test was performed to analyze any gravity effects on the process.

After bonding, additional 3-channel samples were tested for their bond quality by performing a leak test. A leak-proof hermetic bond is a required condition for all microfluidic devices. To perform the leak test, the MECS device was connected to an air supply source. A polydimethylsiloxane (PDMS) gasket was used to seal the opening between device and fixture. The test fixture and device were immersed in water and leakage was detected by watching for the formation of air bubbles up to one minute. The device was pressurized to an air pressure of 1.72 bar (25 psi) and found to be hermetically sealed.

\section{Process Design}

A 355 nm Nd:YAG laser mounted on an ESI 4420 laser micromachining system was used to pattern the copper shims into laminae. Laser burrs of significant height (19.1 
$\pm 8.5 \mu \mathrm{m}$ ) were produced during the cutting process. 3M Scotch Brite heavy duty scour pads were used for the mechanical removal of these burrs. The mechanical deburring process reduced the laser burrs to a mean height of $2.9 \pm 2.3 \mu \mathrm{m}$. Lamina flattening was an important part of the development because of its significance to solder paste printing and for proper solder filling of the copper surface during reflow. A flat substrate surface also helps in producing channels of uniform height. A vacuum hot press was used for flattening laminae. Laminae were sandwiched between thin, flat graphite plates and placed one over the other to form an array. This array of alternate graphite and copper laminae was loaded in the hot press and heated to a temperature of $500^{\circ} \mathrm{C}$ for 30 minutes while applying a flattening pressure of 36.75 bars. This flattening process was done in a vacuum environment of about $1 \times 10^{-4}$ mbar. The fresh shim stock received from the vendor had a mean flatness of $99.9 \pm 32.9 \mu \mathrm{m}$ over a substrate size of $4.44 \times 1.90 \mathrm{~cm}$ (length of scan: $1 \mathrm{~cm}$ ), and the post heat-treated laminae had a mean flatness of $4.73 \pm$ $1.14 \mu \mathrm{m}$ over a substrate size of $4.44 \times 1.90 \mathrm{~cm}$ (length of scan: $1 \mathrm{~cm}$ ).

Wetting of the copper surface by the $\mathrm{SnPb}$ solder was assisted by selectively removing the oxide layer from the copper surface via chemical etching. A $10 \%$ ammonium hydroxide solution and a 3\% hydrogen peroxide solution were mixed together to form the "micro-etch" solution. The micro-etch solution was swabbed onto the lamina areas with the help of a Q-stick. After the micro-etching process, laminae were washed with DI water to remove any excess solution. The microetching also helped to constrain the liquid solder during reflow by surface tension effects.

Solder paste was then printed on the cleaned and micro-etched laminae. An Ekra semi-automatic screen printer was used to apply solder paste. The printing equipment and 
process used for this experiment are standard to the SMT assembly industry. The equipment used is part of a surface mount assembly cell. No modifications were made to the equipment to perform the solder paste printing processes. In printing solder paste, the lamina were held on a Printed Circuit Board (PCB) with the help of Kapton tape. The PCB was placed on the work holder table and held firmly by vacuum. A standard SMT stencil was used to apply solder paste. Dual squeegee passes were used. The line width of printed solder paste was measured as $1.27 \mathrm{~mm}(0.05$ inch). The height of the printed solder paste was assumed to be the same as the height of the stencil i.e. $0.20 \mathrm{~mm}(0.008$ inch).

The stencil design used for printing the solder paste is shown in Figure 3. In the manufacture of the stencil, small areas of stencil material (tie bars) were necessary to create the geometry. Low-residue no-clean flux was applied at the tie-bar areas on all laminae. This flux provided the necessary surface tension for solder to flow in at the tiebar areas during the reflow process.

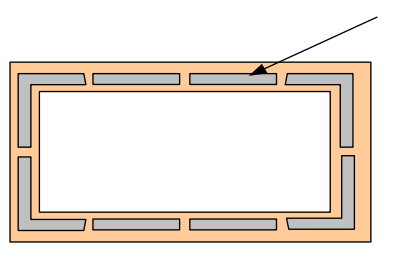

(a)

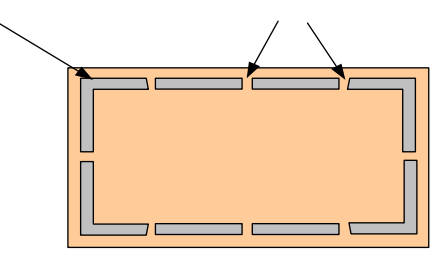

(b)

Figure 3(a) Printed solder paste with tie-bar areas on channel spacer. (b) Printed solder paste with tie-bar areas.

The solder-printed laminae were stacked in the required order to form an array (Figure 4). These laminae were edge-aligned using a graphite fixture. This stacked, 3channel array was then loaded into a vacuum hot press for bonding. Here a vacuum hot 
press was used to simulate the temperature profile experienced within a reflow oven. A slight bonding pressure (0.0187 bar) was applied by placing a small graphite shim on top of the sample. This bonding pressure was obtained through multiple trials. It was found that without this small bonding pressure, the stack of laminae became misaligned. The tension of the molten solder did not appear to be sufficient during the reflow process to maintain the alignment of the stack.

The furnace temperature was ramped at a rate of 19 degrees $\mathrm{C} /$ minute to a temperature of $370^{\circ} \mathrm{C}$ for 2 minutes before cooling to room temperature. Further experiments would be necessary to determine if the bonding process throughput could be improved by heating the structure at a higher rate. The bonding cycle was done in a vacuum environment of approximately $1 \times 10^{-4}$ mbar. Bonding in a vacuum environment helps in the degassing of the solder paste and subsequently prevents post-bonding solder voids.

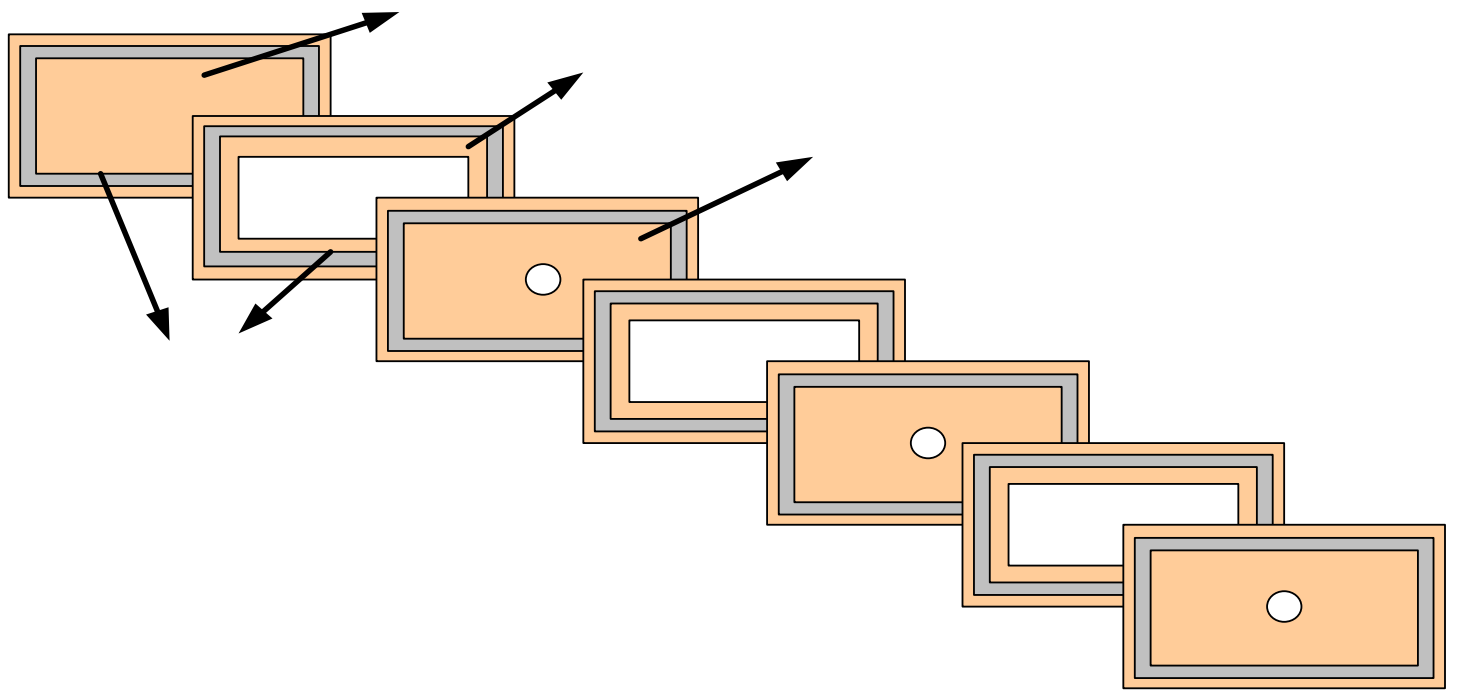

Figure 4. Stacking order of solder-printed laminae for reflow bonding. 


\section{Prediction of Channel Height}

Since channel height (i.e. of the fluid flow passage) non-uniformity reduces the performance of a micro heat exchanger (Wattanutchariya, 2002), it was desirable to predict the resultant channel height of the devices. Therefore, a mathematical model was derived to predict the height of channels in the device using device geometries.

The volume of solder paste printed onto the lamina $\left(\mathrm{V}_{\mathrm{p}}\right)$ is given by the equation:

$$
\mathbf{V}_{\mathbf{p}}=\mathbf{A}_{\mathbf{p}} \cdot \mathbf{t}_{\mathbf{p}}
$$

where, $A_{p}$ is the upward facing solder paste area as shown in Figure 3 , and, $t_{p}$ is the height (thickness) of the printed solder paste (equivalent to the stencil thickness). The volume of solder after reflow (Vs) is therefore:

$$
\mathbf{V}_{\mathrm{s}}=\mathbf{V}_{\mathbf{p}} \cdot \mathbf{S}
$$

where, $\mathrm{V}_{\mathrm{p}}$ is obtained from Equation 1 , and $\mathrm{S}$ is the solids loading of the solder paste. Solids loading is the metal content of a solder paste, expressed in percentage by volume. The resulting solder thickness, $\mathrm{t}_{\mathrm{s}}$ can be predicted using equations 1 and 2 as follows:

$$
\mathbf{t}_{\mathrm{s}}=\frac{\mathbf{V}_{\mathrm{s}}}{\mathbf{A}}
$$

where, $\mathrm{A}$ is the up-facing area of the channel/spacer lamina (Figure 3a). The resulting channel height, h, can be obtained from the following summation:

$$
\mathbf{h}=\mathbf{t}+\mathbf{2} \mathbf{t}_{\mathrm{s}}
$$

where, $\mathrm{t}$ is the lamina thickness. Values for calculating the theoretical channel height are shown in Table 1. 
Table 1. Values of parameters used in the channel height prediction model.

\begin{tabular}{|c|c|}
\hline Parameter & Value \\
\hline Area of solder paste printed $\left(\mathrm{A}_{\mathrm{p}}\right)$ & $1.342 \mathrm{~cm}^{2}$ \\
\hline Height of printed solder paste $\left(\mathrm{t}_{\mathrm{p}}\right)$ & $0.020 \mathrm{~cm}$ \\
\hline Solids Loading $(\mathrm{S})$ & $50 \%$ \\
\hline Spacer Area & $4.258 \mathrm{~cm}^{2}$ \\
\hline Lamina thickness $(\mathrm{t})$ & $0.020 \mathrm{~cm}$ \\
\hline
\end{tabular}

\section{Results and Discussions}

The average top, middle and bottom channel heights and standard deviation for the three samples are shown in Table 2. Figure 5 illustrates a cross-section of one of the microchannel array devices fabricated for this study.

Table 2. Comparison of channel height and standard deviation for the three samples.

\begin{tabular}{|c|c|c|c|c|}
\hline & \multicolumn{3}{|c|}{ Channel } \\
\hline & & Top & Middle & Bottom \\
\hline \multirow[b]{2}{*}{ Sample 1} & Average Channel Height (microns) & 273.7 & 273.0 & 263.0 \\
\hline & Standard Deviation & 1.03 & 1.79 & 2.83 \\
\hline \multicolumn{5}{|c|}{ Percentage variation: $\pm \mathbf{0 . 6 \%}$} \\
\hline \multirow[b]{2}{*}{ Sample 2} & Average Channel Height (microns) & 279.0 & 275.7 & 270.0 \\
\hline & Standard Deviation & 2.83 & 5.16 & 1.09 \\
\hline \multicolumn{5}{|c|}{ Percentage variation: $\pm \mathbf{1 . 1} \%$} \\
\hline \multirow[b]{2}{*}{ Sample 3} & Average Channel Height (microns) & 268.7 & 272.3 & 263.0 \\
\hline & Standard Deviation & 2.94 & 2.06 & 4.19 \\
\hline \multicolumn{5}{|c|}{ Percentage variation: $\pm 1.1 \%$} \\
\hline \multicolumn{2}{|c|}{ Overall Empirical Mean Channel Height } & \multicolumn{3}{|c|}{$270.9 \pm 1.2 \%$} \\
\hline \multicolumn{2}{|c|}{ Theoretical Mean Channel Height } & \multicolumn{3}{|c|}{267.2} \\
\hline
\end{tabular}




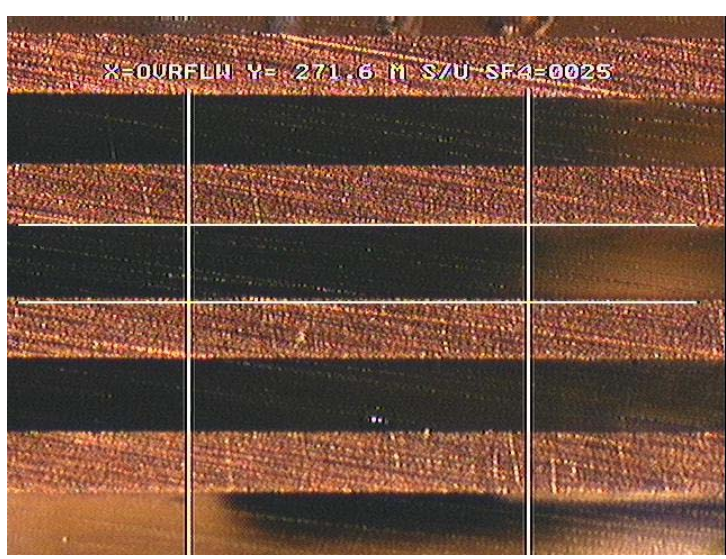

(a)

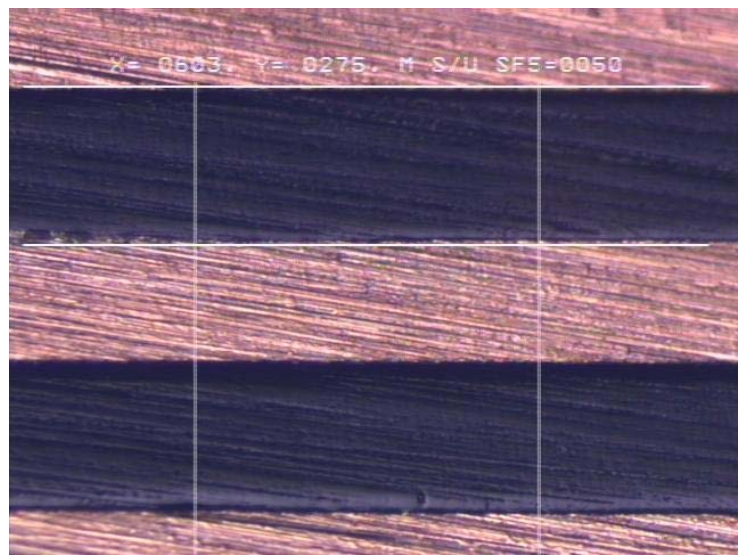

(b)

Figure 5. (a) Cross section of a 42:1 aspect-ratio, 3-microchannel array device. (25X magnification) (b) Micro-channel array with the middle channel height measured to be $271.6 \mu \mathrm{m}$. (50X magnification)

Micro-channels with aspect ratios of $42: 1$ were produced using this technique. The overall mean channel height was $270.9 \mu \mathrm{m}$ and the standard deviation was $3.19 \mu \mathrm{m}$ for the three devices. The overall percent variation in the channel height for the three devices was $\pm 1.2 \%$. Results obtained from the Kruskal-Wallis test comparing the means for the three samples, showed no evidence of differences in the mean ( $p$-value $=0.102$ ). The percentage variation in channel height for the three individual samples was calculated to be $\pm 0.6 \%, \pm 1.1 \%$, and $\pm 1.1 \%$ respectively. The Kruskal-Wallis test showed no evidence of differences (p-value of 0.118 ) in the mean percentage variation for the three channel heights (top, middle and bottom). The average percentage variation in channel height for the top, middle and bottom channels was calculated to be $\pm 0.8 \%$, $\pm 1.1 \%$, and $\pm 1.0 \%$ respectively. Differences in channel heights may have been due to a combination of factors including variation in lamina flatness, bending of laminae during micro-etching, or variation in any of the parameters included in Equations 1-4. 
The microchannel variation resulting from this process is insignificant when compared to devices produced via diffusion bonding. Typical channel height deviations within diffusion bonded stainless steel devices have been found to be from $31.7 \%$ to 7.7\% for channel heights from $50.8 \mu \mathrm{m}$ to101.6 $\mu \mathrm{m}$ respectively (Wattanutchariya, 2002). For microchannels made out of NiAl, Kanlayasiri found variations between 21\% to 37\% (Kanlayasiri, 2004). Past studies have shown that a $20 \%$ channel variation will result in about a 50\% increase in the number of channels needed for a typical microchannel heat exchanger (Wattanutchariya, 2002). The small amount of microchannel height variation is likely the result of lower bonding pressure and temperatures used during reflow. In addition, during bonding, the molten solder is able to redistribute and any sideloading or thermal stresses developed during ramping are relaxed.

Good solder-bond quality was observed, as shown in Figure 6. Small voids were detected at the solder joint. These voids can be attributed to the oxidation of the copper surface, which prevents the formation intermetallic bonds between the solder and substrate, and/or entrapped gases from the flux (O’Hara \& Lee, 1998). The observed voids, however, did not cause leakage in the device. 


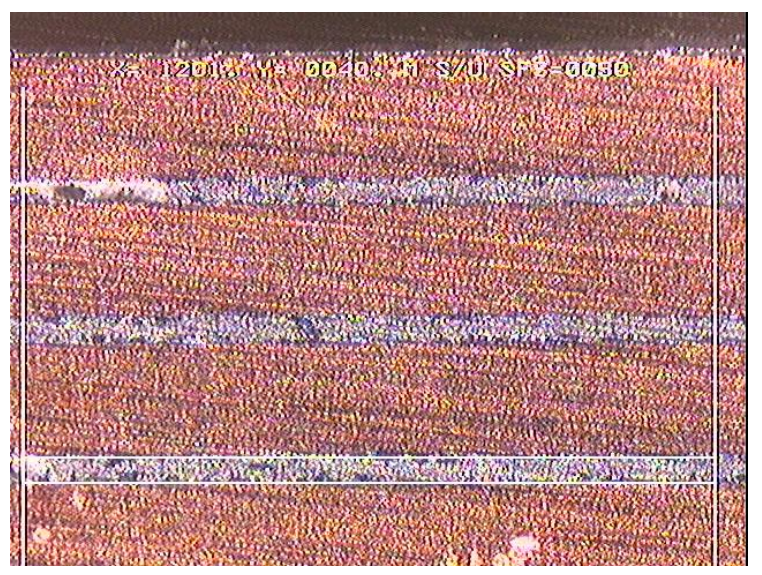

(a)

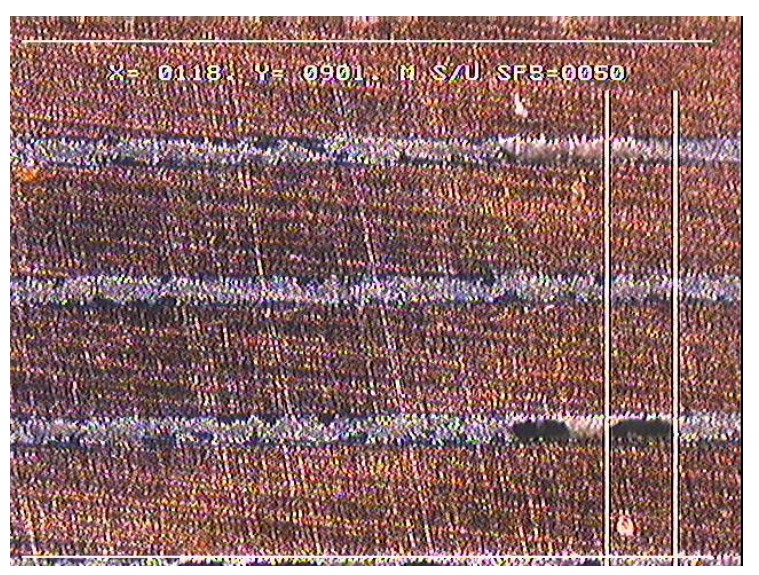

(b)

Figure 6: Solder bond between individual copper lamina. All measurements at 50X magnification. (a) Solder bond with negligible voids and solder layer measured as $40 \mu \mathrm{m}$ thick. (b) Solder layers with small voids (118 $\mu$ m wide).

Another significant achievement of this study was the ability to control the reflow process adjacent to microchannel capillaries. Control of the reflow process was substantiated by generally good agreement between the measured channel heights and the heights predicted by the theoretical model. The predicted channel height was found to be $267.2 \mu \mathrm{m}$ which is just outside the $95 \%$ confidence interval of 267.6 to $274.3 \mu \mathrm{m}$. This is an excellent result considering the number of variables within the model. Any deviation between the theoretical model and the empirical results can be attributed to the small amount of solder detected within the microchannels (Figure 7). This result provides strong evidence that the micro-etching process and the channel/spacer laminae were helpful for restricting the flow of solder during reflow. 

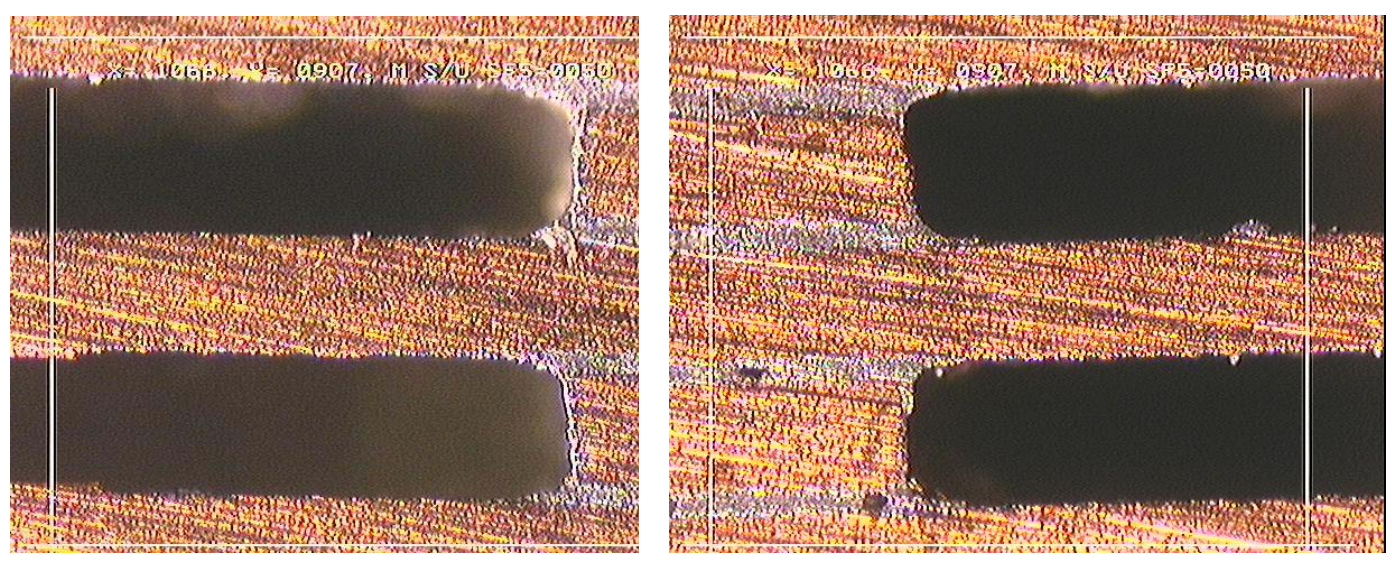

Figure 7: Cross section of device at the edge of channels, showing negligible amount of solder flowing into the channels. (50X Magnification)

Three prototypes were leak tested at an air pressure of 1.72 bar (25 psi). During the test, no air bubbles were detected. It is expected that the solder bond will permit pressure well beyond this amount. The device was not checked beyond these conditions due to line-pressure restrictions in the test fixture.

\section{Conclusions}

This study shows that surface mount technology (SMT) processes can be successfully used to produce leak-proof, high-aspect-ratio (42:1) microchannel arrays in copper with eutectic $\mathrm{Sn} / \mathrm{Pb}$ bonds. The use of low bonding temperatures (under $300^{\circ} \mathrm{C}$ ) and very low pressures ( $<0.1$ bar) results in well aligned, parallel channels with low levels of warpage compared to devices microlaminated using existing diffusion bonding methods. Microchannel arrays were produced with small device-to-device and channelto-channel variation with overall microchannel variation to be less than $\pm 1.2 \%$ for a mean channel height of $270.9 \mu \mathrm{m}$. This variation in channel height is 6 to 30 times less than that found in devices with high-aspect-ratio channels (> 30:1) fabricated using existing diffusion bonding platforms. A simple theoretical model was developed for predicting 
the channel height within the devices. The height of embedded microchannels was found to be within $1.5 \%$ of the predicted values. Devices produced using a standard SMT solder printing process and typical solder paste were found to tolerate air pressure of at least 1.72 bar (25 psi) without leakage, and it is expected that much higher pressures can be withstood. Combined with past studies showing that the economics of SMT processes are favorable, an SMT-based microlamination technique appears to be a promising avenue for producing low-temperature MECS devices. Future research efforts will need to focus on the limits of feature, microchannel and laminate assembly sizes as well as to evaluate the feasibility of using higher temperature solders.

\section{References}

Anderson, J. J., "Brazing of Ink Jet Print Head Components Using Thin Layers of Braze Material,” (U.S. Patent 4,875,619), 1989.

Drost, M. K., “Mesoscopic Heat-Actuated Heat Pump Development,” American Society of Mechanical Engineers, Advanced Energy Systems Division, vol. 39, pg. 9-14, 1999.

Drost, M. K., Wegeng, R. S., Martin, P. M., Brooks, K. P., Martin, J. L., and Call, C., “MicroHeater,” AlChE Spring National Meeting, Atlanta, GA, 2000.

Gabriel, M., Paul, B. K., Wilson, R. D., and Alman, D. E., "Characterization of Metallic Foil Joints Using Diffusion Bonding and Diffusion Soldering in Microtechnology-based Energy and Chemical Systems,” Transactions of NAMRC XXIX, 2001.

Holladay, J. D., Jones, E. O., Phelps, M., and Hu, J., "Microfuel Processor for Use in a Miniature Power Supply,” Journal of Power Sources, vol. 108, pg. 21-27, 2002.

Kanlayasiri, K. and Paul, B.K., “A Nickel Aluminide Microchannel Array Heat Exchanger for High-Temperature Applications,” J. Mfg Processes, vol. 6, n. 1, pg. 17-25, 2004.

Martin, P. M., Bennett, W. D., and Johnston, J. W., "Microchannel Heat Exchangers for Advanced Climate Control,” Proceedings of SPIE-The International Society for Optical Engineering, vol. 2639, pg. 82-88, 1995. 
Martin, P. M., Matson, D. W., Bennett, W. D., and Hammerstrom, D. J., "Fabrication of Plastic Microfluidic Components,” Proceedings of SPIE-The International Society for Optical Engineering, vol. 3515, pg. 172-176, 1998.

Martin, P. M., Matson, D. W., and Bennett, W. D., "Microfabrication Methods for Microchannel Reactors and Separations Systems,” Chemical Engineering Communications, vol. 173, pg. 245-254, 1999.

O’Hara, W. B. and Lee, N. C., “SMT Surface Mount Technology Magazine,” vol. 12, n. 4, pg. 68-72, Apr. 1998.

Palmer, J., Zeng, L., and Penny, R., "Comparison of Micromixer with Conventional Static Mixer for Use in Fast Competitive Reactions,” Proceedings of SPIE, vol. 4560, pg. 244-249, Oct. 2001.

Paul, B. K., Hasan, H., Thomas, J., Wilson, R., and Alman, D., "Limits on Aspect Ratio in Two-fluid Micro-scale Heat Exchangers,” Transactions of NAMRC XXIX, pg. 461468, 2001.

Paul, B. K. and Peterson, R. B., "Microlamination for Microtechnology-based Energy, Chemical, and Biological Systems,” ASME IMECE, pg. 45-52, Nov 1999.

Paul, B. K. and Terhaar, T., “Comparison of Two Passive Microvalve Designs for Microlamination Architectures,” Journal of Micromechanics and Microengineering, vol. 10, pg. 15-20, 2000.

Porter, J. D., Paul, B. K., and Ryuh, B., "Cost Drivers in Microlamination Based on a High-Volume Production System Design,” ASME IMECE, pg. 276-274, Nov. 2002.

Sharma, N. and Paul, B. K., "The Application of Surface Mount Technology to MultiScale Process Intensification,” ASPE National Conference, Oct 2003.

Sharma, N., Porter, J. D., and Paul, B. K., “Understanding Cost Drivers in Microlamination Approaches to Microsystem Development,” IIE IERC, May 2003.

TeGrotenhuis, W. E., Cameron, R. J., Butcher, M. G., Martin, P. M., and Wegeng, R. S., "Micro-Channel Devices for Efficient Contact of Liquids in Solvent Extraction," Separation Science and Technology, vol. 34, n. 6-7, pg. 951-974, 1999.

Tonkovich, A. Y., Zilka, J. L., LaMont, M. J., Wang, Y., and Wegeng, R. S., "Microchannel Reactors for Fuel Processing Applications, I. Water Gas Shift Reactor," Chemical Engineering Science, vol. 54, n. 13-14, pg. 2947-2951, 1999.

Wattanutchariya, W. “Application of Buckling Behavior to Evaluate and Control Shape Variation in High-Temperature Microlamination,” Ph.D. Dissertation, 2002. 
Wattanutchariya, W. and Paul, B. K., "Bonding Fixture Tolerances for High-Volume Metal Microlamination Based on Fin Buckling and Laminae Misalignment Behavior," Precision Engineering, vol. 28, n. 2, pg. 117-128, 2004.

Wegeng, R. S., Drost, M. K., and McDonald, C. E., "Microcomponent Sheet Architecture," (U.S. Patent 5,611,214), 1997. 